\title{
Determinação das perdas endógenas e da digestibilidade ileal da proteína e dos aminoácidos em suínos utilizando-se duas técnicas ${ }^{1}$
}

\author{
Leidimara Feregueti Costa ${ }^{2}$, Darci Clementino Lopes $^{3}$, Letícia Silva de Freitas ${ }^{2}$, Melissa \\ Izabel Hannas ${ }^{4}$, Júlio Maria Ribeiro Pupa ${ }^{4}$, Anderson Corassa ${ }^{2}$
}

\footnotetext{
1 Trabalho parcialmente financiado pela empresa Alltech.

2 Programa de Pós-graduacao em Zootecnia - Universidade Federal de Viçosa, DZO - UFV, Viçosa, MG, CEP: 36571-000. Bolsista do CNPq.

${ }^{3}$ Departamento de Zootecnia - Universidade Federal de Viçosa, Viçosa - MG, CEP: 36571-000.

${ }^{4}$ All nutri, Viçosa - MG, CEP: 36571-000.
}

RESUMO - Objetivou-se neste estudo determinar os coeficientes de digestibilidade ileal verdadeira da proteína e dos aminoácidos digestíveis de um extrato protéico de levedura utilizando-se duas técnicas - dieta isenta de proteína (DIP) e dieta com caseína hidrolisada enzimaticamente (CHE) - para determinação das perdas endógenas de proteína, aminoácidos e nitrogênio. Foram utilizados 12 suínos mestiços, machos castrados, com peso médio de $35 \mathrm{~kg}$, submetidos previamente a cirurgia para implantação da cânula $\mathrm{T}$ simples. O delineamento experimental foi o inteiramente casualizado com três tratamentos (dieta com CHE; dieta isenta de proteína (DIP); e dieta com 23\% do extrato protéico de levedura - ingrediente teste), quatro repetições e um animal por unidade experimental. As perdas endógenas de ácido glutâmico, ácido aspártico, lisina, arginina e serina diferiram entre as dietas; os maiores valores foram obtidos nos animais que receberam a dieta com CHE. O maior valor de perda endógena do aminoácido glicina foi determinado nos animais alimentados com a dieta DIP. Os coeficientes de digestibilidade ileal verdadeira de metionina, treonina, triptofano e serina determinados pelas perdas endógenas utilizando-se a dieta CHE foram superiores àqueles determinados utilizando a dieta DIP. As quantidades das secreções protéicas e de aminoácidos obtidas pela técnica da CHE foram maiores que as determinadas pela técnica da DIP. Os coeficientes de digestibilidade verdadeira da proteína foram menores e os dos aminoácidos, maiores, quando determinados pela técnica CHE.

Palavras-chave: aminoácidos digestíveis, dieta isenta de proteína, suínos machos castrados

\section{Use of different techniques to determine endogenous losses and ileal digestibility of protein and amino acids for swine}

\begin{abstract}
The objective of this study was to determine the true ileal digestibility coefficients of the protein and digestible amino acid of a yeast protein extract using two techniques - diet without protein (DIP) and diet with enzimehydrolysed casein (CHE) - for the determination of protein amino acid and nitrogen losses. Twelve half-breed barrows were used, with average weight of $35 \mathrm{~kg}$, previously submitted to a surgery for "T" simple cannula implantation. A completely randomized experimental design with three treatments, four replications and one animal per experimental unit was used. The treatments diets with CHE, DIP diet with 23\% CP were constituted by yeast protein extract. Endogenous losses of glutamic acid, aspartic acid, lysine, arginine and serine differ among diets, the higher values were observed for animals consumed CHE diet. The higher endogenous losses values observed for glycine was determined in the animals fed DIP diet. The true ileal digestibility coefficients of methionine, threonine, tryptophan and serine determined with the endogenous losses using CHE diet were higher than those determined using DIP diet. The amounts of protein and amino acids secretions obtained by using CHE technique were higher than those obtained by the DIP technique. True protein digestibility coefficients of protein were lower and amino acid higher when determined by CHE technique.
\end{abstract}

Key Words: barrows, diet without protein, digestible amino acids

\section{Introdução}

As técnicas para determinação da digestibilidade ileal in vivo em suínos podem ser o método do sacrifício ou abate, a cânula T simples, a cânula pós-valvular em T(PVTC), as cânulas reentrantes e a anastomose íleo-retal.

A diferença entre digestibilidade e a disponibilidade dos aminoácidos (Willians, 1995) deve ser considerada 
na escolha da técnica a ser utilizada. A digestibilidade aparente dos aminoácidos é definida como a porção do nutriente do alimento fornecido que "desaparece" no trato digestório. Quando se consideram as perdas endógenas e metabólicas, são estimados os valores de digestibilidade verdadeira dos aminoácidos. A disponibilidade, no entanto, é a porção de um aminoácido no alimento que é digerida, absorvida e utilizada para a síntese de proteínas.

As fontes de proteína e aminoácidos endógenos consistem principalmente de enzimas digestivas, mucoproteínas, descamação da parede da mucosa, albumina, peptídeos, aminoácidos livres, aminas e uréia (Moughan \& Schuttert, 1991). De acordo com Moughan (2003), o nitrogênio secretado no trato digestório de suínos é hidrolisado e reabsorvido antes de alcançar o íleo distal, processo denominado reciclagem de proteína e aminoácidos endógenos (Grala et al., 1998).

A digestibilidade ileal aparente é influenciada pelo nível protéico da dieta (Donkoh et al., 1994). Assim, em quantidades diferentes de proteína na dieta, os ingredientes devem ser comparados utilizando-se a determinação da digestibilidade ileal verdadeira (Fan \& Sauer, 1995).

Os valores de digestibilidade ileal de aminoácidos em concentrados protéicos que sofreram danos térmicos durante o tratamento muitas vezes são impróprios para formulação de dietas e resultam em utilização ineficiente dos aminoácidos (Batterham et al., 1993). De acordo com Batterham \& Andersen (1994) e Batterham et al. (1994), a isoleucina é menos susceptível aos efeitos do calor que outros aminoácidos, como lisina, treonina, metionina e triptofano.

A variabilidade nos dados de digestibilidade ileal é determinada por fatores inerentes aos alimentos, como: inibidores de proteases, fitohemoaglutininas, fibra, oligossacarídeos, enzimas, tanino, tamanho de partícula e processamento (Bellaver, 2003), e também pode estar relacionada à técnica utilizada para determinação das perdas endógenas, uma vez que as perdas endógenas ileais dos aminoácidos diferem entre as técnicas (Donkoh \& Moughan, 1999; Hodgkinson et al., 2003).

Alguns fatores como o tipo e nível de fibra utilizados na dieta também podem influenciar a determinação das perdas endógenas (Low, 1982; Lenis et al., 1996; Nyachoti et al., 1997; Pozza et al., 2003).

A utilização de caseína enzimaticamente hidrolisada como única fonte protéica na dieta dos animais e a utilização de dieta isenta de proteína são as técnicas mais utilizadas para determinação das perdas endógenas. A caseína enzimaticamente hidrolisada é composta de aminoácidos livres e pequenos peptídeos com peso molecular inferior a 5.000 Da. Por esta técnica, presume-se que o consumo de dieta contendo proteína possibilita o funcionamento fisiológico normal do organismo animal e que todo o nitrogênio componente da proteína endógena possua peso molecular maior que 10.000 Da e pode ser separado por meio de centrifugação e ultrafiltragem da fração não absorvida dos aminoácidos da dieta com caseína.

A utilização de dietas isentas de proteína (DIP), no entanto, possibilita estimar a quantidade de substâncias endógenas não-reabsorvidas. Assume-se que essa fração endógena excretada seja constante e que o valor para a excreta no balanço aparente pode ser corrigido para cálculo da digestibilidade verdadeira (Laplace, 1996). Entretanto, o fornecimento de uma dieta sem nenhuma fonte de proteína promove um comportamento fisiológico do organismo animal, tanto na síntese enzimática como protéica, diferente do observado em animais alimentados com dieta contendo alguma fonte protéica.

Diante do exposto, realizou-se este trabalho com o objetivo de determinar os coeficientes de digestibilidade ileal verdadeira da proteína e dos aminoácidos digestíveis de um extrato protéico de levedura utilizando-se duas técnicas: dieta isenta de proteína (DIP); e dieta com caseína hidrolisada enzimaticamente para determinação das perdas endógenas de proteína, aminoácidos e nitrogênio.

\section{Material e Métodos}

O experimento foi conduzido no Setor de Suinocultura do Departamento de Zootecnia da Universidade Federal de Viçosa (UFV) no mês de junho de 2004.

Avaliou-se a digestibilidade dos aminoácidos de extrato protéico de levedura empregando-se a técnica de digestibilidade ileal com determinação das perdas endógenas. Foram utilizados 12 animais machos castrados, mestiços (Landrace $\times$ Large White), adquiridos no setor de melhoramento genético da UFV, com peso médio inicial de $35 \mathrm{~kg}$.

Os animais foram submetidos a cirurgia para implante de cânula T simples no íleo distal a 20 cm da válvula íleo-cecal, segundo técnica adaptada de Donkoh et al. (1994).

Odelineamento experimental foi inteiramente casualizado, com três tratamentos, cada um com quatro repetições e um animal por unidade experimental. Os tratamentos consistiram de: dieta com caseína hidrolisada enzimaticamente (CHE); dieta isenta de proteína; e dieta com $23 \%$ do extrato protéico de levedura - ingrediente teste.

As dietas (Tabela 1) foram formuladas à base de amido de milho, óleo de soja, celulose purificada, açúcar, minerais 
e vitaminas para atender às exigências nutricionais dos animais, descritas por Rostagno et al. (2000). O balanço eletrolítico das dietas foi corrigido quanto aos teores de minerais, potássio, sódio, magnésio, cálcio e fósforo (Tabela 2).

A dieta com caseína hidrolisada e aquela isenta de proteína foram utilizadas para determinação da excreção endógena de proteínas e aminoácidos. Às dietas experimentais adicionou-se $0,5 \%$ de óxido crômico $\left(\mathrm{Cr}_{2} \mathrm{O}_{3}\right)$ como indicador para determinação da digestibilidade.

O ensaio de digestibilidade teve duração de sete dias: três para adaptação, dois para regularização do fluxo intestinal e dois para coleta de digesta.

A quantidade de ração fornecida a cada animal durante o controle do fluxo foi calculada com base no peso metabólico $\left(\mathrm{kg}^{0,75}\right)$. Nos períodos de adaptação, de controle de fluxo e de coleta, a dieta foi fornecida duas vezes ao dia (8 h e 11 h), em intervalos de 3 horas, utilizando-se $10 \%$ do peso metabólico para cada animal nos tratamentos com caseína e concentrado-protéico-teste. Para a DIP, a quantidade fornecida foi calculada com base no consumo metabólico determinado no período do controle do fluxo. Para evitar perdas e facilitar a ingestão, as rações foram umedecidas com água na proporção de 1:1.

As coletas das digestas iniciaram-se logo após a alimentação e se estenderam por 10 horas. As amostras foram coletadas em sacos de polietileno presos à cânula e, posteriormente, colocadas em sacos plásticos, que foram identificados e armazenados em congelador $\left(-5^{\circ} \mathrm{C}\right)$ até o final do período de coleta. As amostras compostas da digesta de cada animal alimentado com as dietas contendo o extrato protéico de levedura - ingrediente teste e com a DIP foram descongeladas, pesadas, homogeneizadas e congeladas a $-80^{\circ} \mathrm{C}$ para posterior liofilização.

Nas amostras da digesta dos animais alimentados com a dieta contendo CHE, foram feitos os ajustes de $\mathrm{pH}$ para 3,5 , adicionando-se uma solução de $\mathrm{H}_{2} \mathrm{SO}_{4} 9 \mathrm{~mol} / \mathrm{L}$ imediatamente após a coleta para reduzir a atividade enzimática e bacteriana nas amostras.

Ao final dos dois dias de coleta, as amostras foram descongeladas a $4^{\circ} \mathrm{C}$ e encaminhadas ao Instituto de Biotecnologia Aplicada à Agronomia - BIOAGRO, da Universidade Federal de Viçosa, onde foram submetidas a centrifugação a 1.450 giros ( $3.100 \mathrm{rpm}$ ) por 45 minutos a $0^{\circ} \mathrm{C}$. Em seguida, o sobrenadante foi retido e o precipitado lavado com $5 \mathrm{~mL}$ de água destilada. Novamente, o precipitado foi centrifugado por mais 30 minutos, também a $0^{\circ} \mathrm{C}$. Os precipitados foram guardados a $-80^{\circ} \mathrm{C}$ e liofilizados. $\mathrm{O}$ sobrenadante foi filtrado em célula de ultrafiltragem,
Tabela 1 - Composição das dietas experimentais

\begin{tabular}{|c|c|c|c|}
\hline Ingrediente & $\mathrm{CHE}^{1}$ & $\mathrm{DIP}^{2}$ & $\begin{array}{c}\text { Concentrado } \\
\text { protéico }^{1}\end{array}$ \\
\hline Caseína $^{3}$ & 10,000 & - & - \\
\hline Núcleo protéico & - & - & 23,000 \\
\hline Amido & 69,855 & 79,855 & 59,390 \\
\hline Açúcar & 8,000 & 8,000 & 8,000 \\
\hline Óleo de soja refinado & 2,000 & 2,000 & 2,000 \\
\hline Celulose purificada ${ }^{4}$ & 3,000 & 3,000 & 3,000 \\
\hline Sal & 0,400 & 0,400 & 0,040 \\
\hline Fosfato bicálcico & 1,960 & 1,960 & 1,460 \\
\hline Calcário & 0,760 & 0,760 & 1,000 \\
\hline Sulfato de magnésio & 1,180 & 1,180 & 0,470 \\
\hline Cloreto de potássio & 0,570 & 0,570 & 0,970 \\
\hline Carbonato de potássio & 0,900 & 0,900 & 0,080 \\
\hline Carbonato de sódio & 0,560 & 0,560 & - \\
\hline Cloreto de colina & 0,165 & 0,165 & 0,020 \\
\hline Premix vitamínico 5 & 0,100 & 0,100 & 0,100 \\
\hline Premix mineral ${ }^{6}$ & 0,050 & 0,050 & 0,050 \\
\hline Óxido de cromo & 0,500 & 0,500 & 0,500 \\
\hline \multicolumn{4}{|l|}{ Composição calculada (\%) } \\
\hline Proteína bruta (\%) & 9,260 & 0,450 & 12,090 \\
\hline Energia digestível (kcal/kg) & 3,495 & 3,452 & 3,424 \\
\hline Fibra bruta (\%) & 3,000 & 3,000 & 3,090 \\
\hline $\mathrm{Ca}(\%)$ & 0,760 & 0,760 & 0,760 \\
\hline Fósforo disponível (\%) & 0,360 & 0,360 & 0,360 \\
\hline $\mathrm{Na}(\%)$ & 0,400 & 0,400 & 0,400 \\
\hline $\mathrm{Cl}(\%)$ & 0,500 & 0,500 & 0,500 \\
\hline K (\%) & 0,900 & 0,900 & 0,900 \\
\hline $\mathrm{Mg}(\%)$ & 0,140 & 0,140 & 0,140 \\
\hline
\end{tabular}

${ }^{1}$ Dieta isenta de proteína.

2 Dieta com caseína hidrolizada enzimaticamente.

3 Caseína hidrolisada enzimaticamente - SIGMA Alldrich.

${ }^{4}$ Celulose microcristalina 101-LT:106 - Cl: 002778/04-001338 - Henrifarma produtos químicos e farmacêuticos Ltda.

${ }^{5}$ Conteúdo/kg: vit. A - 10.000 .000 U.I.; vit. $\mathrm{D}_{3}-1.500 .000$ U.I.; vit. $\mathrm{B}_{1}$ $2,0 \mathrm{~g}$; vit. $B_{2}-5,0 \mathrm{~g}$; vit. $B_{6}-3,0 \mathrm{~g}$; vit. $B_{12}-30.000 \mathrm{mcg}$; ácido nicótico - 30,000 mg; ácido pantotênico - $12.000 \mathrm{mcg}$; vit. $\mathrm{K}_{3}-2.000 \mathrm{mg}$; ácido fólico - $800 \mathrm{mg}$; biotina - $100 \mathrm{mg}$; Se - $300 \mathrm{mg}$; veículo q.s.p. - $1.000 \mathrm{~g}$ ${ }^{6}$ Conteúdo/kg: Fe - 100 g; Cu - 10 g; Co - 1g; Mn - 40 g; Zn - 100 g; I - 1.5 g veículo q.s.p. - $500 \mathrm{~g}$.

sempre mantida no gelo, com pressão de 20 psi, utilizando-se uma membrana de celulose regenerada com volume de exclusão de 10.000 Da e diâmetro de 76 mm (Millipore no 13.642). Posteriormente, o sobrenadante foi congelado também a $-80^{\circ} \mathrm{C}$ para separação molecular das proteínas (PM > 10.000 Da), dos peptídeos e aminoácidos livres $(\mathrm{PM}<10.000 \mathrm{Da})$. A fração retida na membrana, isto é, a fração da amostra com peso molecular maior que $10.000 \mathrm{Da}$, foi adicionada ao precipitado e o material foi liofilizado, moído e armazenado a $-20^{\circ} \mathrm{C}$ para posterior análise bromatológica.

Os teores de matéria seca, proteína bruta e cromo das digestas e das rações experimentais foram determinados no Laboratório do CBO Assessoria e Análises, em Campinas, SP, de acordo com as metodologias descritas por Silva (1990). As composições em aminoácidos das digestas e 
Tabela 2 - Composição protéica e aminoacídica das dietas experimentais e do extrato protéico de levedura (\% MS)

\begin{tabular}{lcccc}
\hline & Dieta-teste* & CHE * & DIP* & $\begin{array}{c}\text { Concentrado } \\
\text { protéico }\end{array}$ \\
\hline $\begin{array}{l}\text { Proteína bruta } \\
\text { Aminoácidos }\end{array}$ & 11,040 & 9,730 & 0,380 & 48,000 \\
Lisina & 0,580 & 0,680 & 0,005 & 2,523 \\
Metionina & 0,140 & 0,110 & 0,100 & 0,609 \\
Ácido aspártico & 0,750 & 0,580 & 0,010 & 3,261 \\
Ácido glutâmico & 1,126 & 2,080 & 0,010 & 4,896 \\
Serina & 0,420 & 0,400 & 0,004 & 1,826 \\
Glicina & 0,420 & 0,160 & 0,007 & 1,826 \\
Histidina & 0,240 & 0,260 & 0,006 & 1,043 \\
Arginina & 0,500 & 0,340 & 0,008 & 2,174 \\
Treonina & 0,428 & 0,190 & 0,011 & 1,862 \\
Alanina & 0,610 & 0,280 & 0,011 & 2,652 \\
Prolina & 0,540 & 0,860 & 0,013 & 2,348 \\
Tirosina & 0,380 & 0,460 & 0,005 & 1,652 \\
Valina & 0,560 & 0,600 & 0,008 & 2,435 \\
Cistina & 0,130 & 0,040 & 0,006 & 0,565 \\
Isoleucina & 0,480 & 0,470 & 0,004 & 2,087 \\
Leucina & 0,850 & 0,880 & 0,015 & 3,696 \\
Fenilalanina & 0,480 & 0,470 & 0,007 & 2,087 \\
Triptofano & 0,108 & 0,110 & 0,000 & 0,470 \\
\hline
\end{tabular}

*Valores analisados no Laboratório CBO Assessoria e Análises, Campinas, SP.

${ }^{1}$ Composição química do alimento na matéria natural.

rações foram determinadas por meio de cromatografia líquida de alta performance (HPLC).

A digestibilidade ileal dos aminoácidos foi determinada pelo cálculo do fator de indigestibilidade, utilizando-se as fórmulas descritas por Rostagno \& Featherston (1977):

a) cálculo do fator de indigestibilidade $\left(\mathrm{FI}_{1}\right)$ :

$$
\mathrm{FI}_{1}=\frac{\mathrm{Cr}_{2} \mathrm{O}_{3} \text { dieta }}{\mathrm{Cr}_{2} \mathrm{O}_{3} \text { digesta }}
$$

em que: $\mathrm{Cr}_{2} \mathrm{O}_{3}=$ concentração de óxido crômico.

b) coeficiente de digestibilidade aparente da proteína bruta $\left(\mathrm{CD}_{\mathrm{ap}} \mathrm{PB}\right)$ :

$$
\mathrm{CD}_{\mathrm{ap}} \mathrm{PB}=\frac{\text { PB dieta }-\left(\mathrm{PB} \text { digesta } \times \mathrm{FI}_{1}\right)}{\text { PB dieta }} \times 100
$$

em que: $\mathrm{PB}$ = proteína bruta

c) coeficiente de digestibilidade verdadeira da proteína $\left(\mathrm{CD}_{\mathrm{v}} \mathrm{PB}\right)$ :

$$
\mathrm{CD}_{\mathrm{v}} \mathrm{PB}=\frac{\mathrm{PB} \text { dieta }-\left(\mathrm{PB} \text { digesta } \times \mathrm{FI}_{1}-\mathrm{PB}_{\mathrm{e}} \times \mathrm{FI}_{2}\right)}{\text { PB dieta }} \times 100
$$

em que: $\mathrm{PB}_{\mathrm{e}}=\mathrm{PB}$ endógena excretada nas digestas; e $\mathrm{FI}_{2}=$ fator de indigestibilidade da DIP ou da dieta com CHE.

d) coeficiente de digestibilidade aparente de aminoácidos $\left(\mathrm{CD}_{\mathrm{ap}} \mathrm{AA}\right)$ :

$$
\mathrm{CD}_{\mathrm{ap}} \mathrm{AA}=\frac{\mathrm{mg} \mathrm{AA} / \mathrm{g} \text { dieta }-\mathrm{mg} \mathrm{AA} / \mathrm{g} \mathrm{E}_{1} \times \mathrm{FI}_{1}}{\mathrm{mg} \mathrm{AA} / \mathrm{g} \text { dieta }} \times 100
$$

em que: $\mathrm{E}_{1}=$ digesta da dieta-teste

e) coeficiente de digestibilidade verdadeira de aminoácido $\left(\mathrm{CD}_{\mathrm{v}} \mathrm{AA}\right)$ :

$\mathrm{CD}_{\mathrm{v}} \mathrm{AA}=\frac{\mathrm{mg} \mathrm{AA} / \mathrm{g} \text { dieta }-\left(\mathrm{mg} \mathrm{AA} / \mathrm{g} \mathrm{E}_{1} \times \mathrm{FI}_{1}-\mathrm{mg} \mathrm{AA} / \mathrm{g} \mathrm{E}_{2} \times \mathrm{FI}_{2}\right.}{\mathrm{mg} \mathrm{AA} / \mathrm{g} \text { dieta }} \times 100$

em que: $\mathrm{E}_{2}=$ digesta da DIP ou dieta com CHE; $\mathrm{FI}_{2}=$ fator de indigestibilidade da DIP ou da dieta com CHE.

f) matéria seca digestível (MSD):

$$
\operatorname{MSD}(\%)=100-\left(\mathrm{FI}_{1} \times 100\right)
$$

g) perdas de aminoácidos endógenos $\mathrm{AA}_{\mathrm{e}}$ :

$$
\mathrm{AA}_{\mathrm{e}}\left(\mathrm{mg} / \mathrm{kg} \mathrm{MS} \text { CONSUMIDA }_{\text {A }}\right)=\mathrm{AA}_{\mathrm{e} \times} \mathrm{FI}_{2}
$$

em que: $\mathrm{AA}_{\mathrm{e}}=$ concentração de aminoácido endógeno ( $\mathrm{mg} / \mathrm{kg}$ matéria seca consumida) $/ \mathrm{FI}_{2}=$ fator de indigestibilidade da DIP ou da dieta com CHE (g/kg).

\section{Resultados e Discussão}

O volume médio de fluido ileal coletado foi de $1.200 \mathrm{~mL}$ por animal e o volume médio de líquido retido na membrana de celulose após a ultrafiltração, $180 \mathrm{~mL}$ por animal.

Não foram observadas diferenças estatísticas entre os valores de proteína bruta determinados com a dieta com DIP e aqueles obtidos com a dieta CHE (Tabela 3). As perdas endógenas de aminoácidos determinadas nas digestas de animais alimentados com DIP, em valores absolutos de aminoácidos totais essenciais e não-essenciais, foram inferiores às determinadas nas digestas dos animais alimentados com a dieta com CHE, com exceção dos aminoácidos metionina, cistina, glicina e prolina.

Esses resultados estão de acordo, em parte, com os descritos por Donkoh \& Moughan (1999), que observaram valores absolutos das perdas endógenas de todos os aminoácidos determinados com CHE superiores aos determinados com DIP. Assim, o consumo de dietas com proteína, mesmo considerando $100 \%$ de absorção, como no caso da caseína hidrolizada enzimaticamente, tende a aumentar as concentrações de proteína no fluido ileal.

Os animais alimentados com CHE apresentaram perdas endógenas estatisticamente superiores dos aminoácidos arginina $(\mathrm{P}<0,05)$, lisina $(\mathrm{P}<0,05)$, ácido aspártico $(\mathrm{P}<0,05)$, 
serina $(\mathrm{P}<0,05)$ e ácido glutâmico $(\mathrm{P}<0,01)$ em comparação aos alimentados com DIP. Em valores absolutos, os animais alimentados com CHE apresentaram secreções dos aminoácidos arginina, lisina, ácido aspártico, serina e ácido glutâmico, 35, 53, 231, 65, e 92\% superiores, respectivamente, às obtidas nos alimentados com DIP.

As perdas endógenas de glicina determinadas com a dieta DIP foram estatisticamente superiores $(\mathrm{P}<0,05)$ às determinadas com a dieta CHE. Para os demais aminoácidos, não foram verificadas diferenças estatísticas significativas $(\mathrm{P}>0,05)$ entre as perdas endógenas determinadas com CHE e DIP.

Jansman et al. (2002) determinaram aumento das secreções endógenas utilizando o método da CHE para os seguintes aminoácidos: glutamina (8,40 g/16 g N), serina (26,86 g/ $16 \mathrm{~g} \mathrm{~N})$, isoleucina (18,75 g/16g N), treonina (4,94 g/16 g N), valina (4,22 g/16 g N), histidina (23,23 g/16 g N), alanina (12,91 g/16 g N) e ácido aspártico (13,80 g/16 g N) em comparação ao método da DIP.

Os valores absolutos das perdas endógenas no fluido ileal foram relativamente baixos para metionina e cistina pelas duas metodologias avaliadas neste estudo, o que pode ser explicado, em parte, pelo baixo conteúdo de aminoácidos sulfurados, tanto na camada de mucina quanto em secreções pancreáticas, em comparação aos demais aminoácidos (Pozza et al., 2003). Esses resultados confirmam os de Hodgkinson et al. (2000), que observaram redução do nível de cistina em animais alimentados com DIP durante oito dias. Esses autores afirmaram que pode haver redução de secreções ricas em aminoácido sulfurado.

De modo geral, o teor de treonina nas secreções endógenas ileais foi elevado, independentemente da técnica utilizada, o que pode estar relacionado ao aumento de glicoproteínas provenientes do muco intestinal, que são ricas nesse aminoácido, assim com relatado por Grala et al. (1998).

De forma semelhante, os elevados teores de ácidos aspártico e glutâmico e leucina podem estar associados a uma relativa proporção desses ácidos no suco pancreático de suínos (Pohland et al., 1993), além da contribuição na camada de mucina.

A maior parte das proteínas endógenas restantes é originada da desconjugação de sais biliares e mucoglicoproteínas, uma vez que esses componentes geralmente são resistentes à ação das enzimas proteolíticas e não sofrem, portanto, reabsorção (Stein et al., 1999). A glicina compõe aproximadamente $90 \%$ do total dos aminoácidos da bile e as mucoglicoproteínas são ricas em prolina, glutamina, ácidos aspárticos, serina e treonina (Huang et al., 1999).
Tabela 3 - Perdas de proteína e aminoácidos ileais endógenos ( $\mathrm{mg} / \mathrm{kg}$ de matéria seca consumida) determinadas usando dieta isenta de proteína (DIP) e dieta com caseína hidrolisada enzimaticamente (CHE)

\begin{tabular}{|c|c|c|c|}
\hline & $\mathrm{CHE}^{1}$ & $\mathrm{DIP}^{2}$ & $\mathrm{CV} \%^{3}$ \\
\hline Proteína bruta & $9.569,85$ & $10.657,59$ & 13,73 \\
\hline \multicolumn{4}{|l|}{ Aminoácido essencial } \\
\hline Arginina ${ }^{* *}$ & 352,43 & 260,14 & 7,58 \\
\hline Histidina & 154,73 & 138,20 & 15,4 \\
\hline Isoleucina & 325,88 & 268,27 & 15,38 \\
\hline Leucina & 567,33 & 479,63 & 11,50 \\
\hline Lisina ${ }^{* *}$ & 410,46 & 268,27 & 12,04 \\
\hline Metionina & 107,45 & 130,07 & 12,61 \\
\hline Fenilalanina & 320,20 & 276,40 & 11,43 \\
\hline Treonina & 474,93 & 235,75 & 28,60 \\
\hline Valina & 474,93 & 382,08 & 11,97 \\
\hline Triptofano & 152,58 & 70,73 & 29,47 \\
\hline Média & 337,39 & 250,95 & - \\
\hline \multicolumn{4}{|c|}{ Aminoácido não-essencial } \\
\hline Alanina & 462,03 & 447,11 & 10,07 \\
\hline Ácido aspártico*** & 565,18 & 170,72 & 21,62 \\
\hline Ácido glutâmico* & 971,34 & 504,02 & 11,57 \\
\hline Cistina & 96,70 & 97,55 & 13,99 \\
\hline Glicina** & 391,12 & 463,37 & 11,97 \\
\hline Serina $^{* *}$ & 593,12 & 357,69 & 12,18 \\
\hline Prolina & 434,10 & 691,00 & 32,87 \\
\hline Tirosina & 294,41 & 284,53 & 14,75 \\
\hline Média & 476,00 & 377,00 & - \\
\hline
\end{tabular}

1 Dieta contendo caseína hidrolisada enzimaticamente.

2 Dieta isenta de proteína.

${ }^{3}$ Coeficiente de variação (\%).

* Nível de significância pelo teste $F(P<0,01)$.

${ }^{\star *}$ Nível de significância pelo teste $F(P<0,05)$.

Com a inclusão de ingredientes protéicos altamente digestíveis nas dietas, como é o caso da caseína hidrolisada enzimaticamente, parece que o organismo animal tende a aumentar as concentrações protéicas e de aminoácidos no fluido ileal endógeno.

Os coeficientes de digestibilidade verdadeira da proteína bruta (Tabela 4) não diferiram significativamente $(\mathrm{P}>0,05)$ entre as técnicas estudadas, embora o valor absoluto obtido com a técnica da DIP para determinação das perdas endógenas tenha sido $1,42 \%$ superior àquele determinado pela técnica da CHE.

Esse aumento pode ser proveniente do nitrogênio nãoprotéico destinado à síntese de proteína e ter contribuído para o aumento do coeficiente de digestibilidade verdadeira da proteína para a técnica da DIP ou também decorrente do consumo de dieta livre de proteína e ter promovido um estado fisiológico do animal fora do padrão normal, resultando em balanço negativo de nitrogênio.

Evidenciou-se diminuição na atividade de enzimas proteolíticas no pâncreas e no intestino nos animais alimentados com DIP, o que afetou as perdas endógenas e, 
conseqüentemente, ocasionou subestimativa dos valores dos coeficientes de digestibilidade verdadeira dos alimentos, conforme descrito por Donkoh \& Moughan (1999).

Observaram-se maiores valores dos coeficientes de digestibilidade verdadeira do concentrado protéico para os aminoácidos metionina e serina $(\mathrm{P}<0,01)$ e treonina e triptofano $(\mathrm{P}<0,05)$ quando se utilizou a técnica da CHE em comparação à DIP.

Esses resultados podem estar relacionados à presença de peptídeos ativos provenientes da dieta contendo a CHE, que, no intestino, podem estimular a produção do hormônio pancreamicina, que estimula a secreção do suco pancreático rico em tripsinogênio e quimiotripsinogênio, entre outras substâncias (Donkoh \& Moughan, 1999).

O fornecimento de peptídeos ativos estimula o processo secretório no intestino, uma vez que são mais facilmente absorvidos, podendo elevar a quantidade das secreções endógenas e melhorar a eficiência de utilização dos componentes da dieta. O aumento da secreção endógena quando se utiliza dieta com caseína hidrolisa pode ser decorrente também do procedimento de ultrafiltragem. De acordo com Hodginkson et al. (2003), quando se utiliza membrana de filtragem com volume de exclusão de $10.000 \mathrm{Da}$, pode ocorrer aumento das perdas e superestimativa dos coeficientes de digestibilidade verdadeiros.

Os coeficientes de digestibilidade verdadeiro dos os aminoácidos glicina e prolina foram superiores quando determinados com o uso do método da DIP, fato observado também por Jansman et al. (2002). Diferentemente, Donkoh \& Moughan (1999) observaram que, entre esse dois aminoácidos, somente os valores determinados para a glicina foram maiores pelo método da DIP.

Os valores absolutos dos aminoácidos digestíveis determinados pela técnica da CHE foram superiores àqueles determinados com DIP para os aminoácidos lisina, metionina, ácido aspártico, ácido glutâmico, serina, arginina, treonina, alanina, valina, isoleucina, leucina, fenilalanina e triptofano (Tabela 5).

O aumento de 2,87; 10,34 e 7,85\% na digestibilidade dos aminoácidos lisina, metionina e treonina, quando comparada a técnicas de CHE e DIP reflete a importância da utilização da metodologia mais precisa para determinação dos coeficientes de digestibilidade ileal verdadeira dos alimentos.

Ambas as técnicas possibilitam a estimativa das perdas endógenas de aminoácidos. A técnica da CHE permite a determinação da perda endógena de aminoácidos considerando que os animais não estarão em catabolismo acentuado, uma vez que está sendo utilizada uma dieta com
Tabela 4 - Coeficientes de digestibilidade ileal aparente e verdadeira da proteína e dos aminoácidos do extrato protéico de levedura, obtidos usando dieta isenta de proteína (DIP) e dieta com caseína hidrolisada enzimaticamente (CHE) na matéria seca

\begin{tabular}{|c|c|c|c|c|}
\hline & \multicolumn{3}{|c|}{ Coeficiente de digestibilidade (\%) } & \multirow{3}{*}{ CV $(\%)^{3}$} \\
\hline & \multirow[t]{2}{*}{ Aparente } & \multicolumn{2}{|c|}{ Verdadeiro } & \\
\hline & & $\mathrm{DIP}^{1}$ & $\mathrm{CHE}^{2}$ & \\
\hline Proteína bruta & 78,17 & 87,83 & 86,60 & 3,69 \\
\hline \multicolumn{5}{|l|}{ Aminoácido essencial } \\
\hline Arginina & 84,90 & 90,10 & 91,94 & 2,14 \\
\hline Histidina & 82,98 & 88,74 & 89,43 & 2,71 \\
\hline Isoleucina & 80,39 & 85,98 & 87,87 & 2,20 \\
\hline Leucina & 83,23 & 88,7 & 89,91 & 2,03 \\
\hline Lisina & 78,27 & 82,89 & 85,35 & 3,52 \\
\hline Metionina* & 75,90 & 95,06 & 105,22 & 2,82 \\
\hline Fenilalanina & 82,62 & 88,37 & 89,29 & 1,52 \\
\hline Treonina** & 68,80 & 75,29 & 80,88 & 3,51 \\
\hline Valina & 78,19 & 85,01 & 86,67 & 2,20 \\
\hline Triptofano** & 73,64 & 80,19 & 87,76 & 4,90 \\
\hline Média & 78,89 & 86,03 & 89,43 & - \\
\hline \multicolumn{5}{|c|}{ Aminoácido não-essencial } \\
\hline Alanina & 77,21 & 84,54 & 84,78 & 3,67 \\
\hline Ácido aspártico & 81,56 & 83,83 & 89,09 & 8,10 \\
\hline Ácido glutâmico & 81,02 & 85,50 & 89,65 & 4,78 \\
\hline Cistina & 75,74 & 83,24 & 83,18 & 5,34 \\
\hline Glicina & 71,90 & 82,93 & 81,21 & 3,51 \\
\hline Serina* & 66,40 & 74,91 & 80,52 & 2,53 \\
\hline Prolina & 78,20 & 90,99 & 86,24 & 9,40 \\
\hline Tirosina & 79,67 & 87,16 & 87,42 & 2,30 \\
\hline Média & 76,46 & 84,13 & 85,26 & - \\
\hline
\end{tabular}

1 Dieta isenta de proteína.

2 Dieta contendo caseína hidrolisada enzimaticamente.

${ }^{3}$ Coeficiente de variação (\%).

* Nível de significância pelo teste $F(P<0,01)$.

${ }^{* *}$ Nível de significância pelo teste $F(P<0,05)$

10\% de proteína bruta disponível para o animal. O uso da dieta isenta de proteína, no entanto, produz aminoácidos catabólicos que alteram em maior proporção as perdas endógenas de aminoácidos pelos suínos.

A diferença nos valores numéricos dos aminoácidos digestíveis quando utilizadas as diferentes técnicas revela a importância de realização de mais pesquisas para definição da metodologia mais indicada para determinação das perdas endógenas de aminoácidos para suínos.

Considerando que o aumento no valor dos aminoácidos digestível determinado pela técnica da CHE ocorrerá em todos os ingredientes com valor protéico nas rações, estes valores irão interferir na quantidade de nutrientes fornecidos aos animais e suas determinações mais precisas permitirão $\mathrm{o}$ atendimento adequado dos requerimentos nutricionais dos animais. 
Tabela 5 - Conteúdos de proteína e de aminoácidos digestíveis do extrato protéico de levedura determinado com a dieta isenta de proteína (DIP) e com caseína hidrolisada enzimaticamente (CHE) e diferença percentual entre os aminoácidos digestíveis da DIP e CHE

\begin{tabular}{|c|c|c|c|}
\hline & $\mathrm{DIP}^{1}$ & $\mathrm{CHE}^{2}$ & Diferença $(\%)^{3}$ \\
\hline & \multicolumn{3}{|c|}{ Proteína digestível (\%) } \\
\hline & 42,16 & 41,28 & - \\
\hline & \multicolumn{3}{|c|}{ Aminoácido digestível (\%) } \\
\hline Lisina & 2,09 & 2,15 & $+2,87$ \\
\hline Metionina & 0,58 & 0,64 & $+10,34$ \\
\hline Ácido áspartico & 2,73 & 2,90 & $+6,22$ \\
\hline Ácido glutâmico & 4,19 & 4,39 & $+4,77$ \\
\hline Serina & 1,37 & 1,47 & $+7,29$ \\
\hline Glicina & 1,51 & 1,48 & $-1,99$ \\
\hline Histidina & 0,93 & 0,93 & 0,00 \\
\hline Arginina & 1,96 & 2,00 & $+2,04$ \\
\hline Treonina & 1,40 & 1,51 & $+7,85$ \\
\hline Alanina & 2,24 & 2,25 & $+0,04$ \\
\hline Prolina & 2,14 & 2,02 & $-5,61$ \\
\hline Tirosina & 1,44 & 1,44 & 0,00 \\
\hline Valina & 2,07 & 2,11 & $+1,93$ \\
\hline Cistina & 0,47 & 0,47 & 0,00 \\
\hline Isoleucina & 1,79 & 1,83 & $+2,23$ \\
\hline Leucina & 3,28 & 3,32 & $+1,21$ \\
\hline Fenilalanina & 1,84 & 1,86 & $+1,08$ \\
\hline Triptofano & 0,38 & 0,41 & $+7,89$ \\
\hline
\end{tabular}

${ }^{1}$ Dieta isenta de proteína.

2 Dieta contendo caseína hidrolisada enzimaticamente.

3 Diferença percentual entre valores dos aminoácidos digestíveis determinados com CHE e DIP.

\section{Conclusões}

As secreções protéicas e de aminoácidos endógenas ileais produzidas pela técnica da caseína hidrolisada enzimaticamente são maiores que as secreções obtidas pela técnica da dieta isenta de proteína. Os coeficientes de digestibilidade ileal verdadeira da proteína foram menores, porém os coeficientes de digestibilidade verdadeira dos aminoácidos do extrato protéico de levedura determinados pela técnica da caseína hidrolisada enzimaticamente foram maiores que os obtidos com a dieta isenta de proteína.

\section{Literatura Citada}

BATTERHAM, E.S.; ANDERSEN, L.M. Utilization of ileal digestible amino acids by growing pigs: Isoleucine. British Journal of Nutrition, v.71, n.4, p.531-541, 1994.

BATTERHAM, E.S.; ANDERSEN, L.M.; BAIGENT, D.R. Utilization of ileal digestible amino acids by growing pigs: methionine. British Journal of Nutrition, v.70, n.3, p.711720, 1993.

BATTERHAM, E.S.; ANDERSEN, L.M.; BAIGENT, D.R. Utilization of ileal digestible amino acids by growing pigs: tryptophan. British Journal of Nutrition, v.71, n.3, p.345360, 1994.
BELLAVER, C. Digestibilidade ileal de aminoácido e utilização dos valores na formulação de dietas para suíno em crescimento. In: CONGRESSO DE LA AMENA Y I DEL CLANA, 11., 2003, México. Anais... México: 2003. p.225-232.

DONKOH, A.; MOUGHAN, P.J.; SMITH, W.C. Comparison of the slaugther method and simple T-piece cannulation of the terminal ileum for determining ileal amino acid digestibility in meat and bone meal for the growing pig. Animal Feed Science and Technology, v.49, n.1-2, p.43-56, 1994.

DONKOH A.; MOUGHAN, P.J. Endogenous ileal nitrogen and amino acid flows in the growing pig receiving a protein - free and diets containing enzymically hydrolysed casein or grade levels of meat and bone meal. British Society of Animal Science, v.68, p.511-513, 1999.

FAN, M.Z.; SAUER, W.C. Determination of apparent ileal amino acid digestibility in barley and canola meal for pigs with the direct; difference; and regression methodos. Journal of Animal Science, v.73, p.2364-2374, 1995.

GRALA, W.; VERSTEGEN, M.W.A.; JANSMAN, A.J.M. et al. Ileal apparent protein and amino acid digestibilities and endogenous nitrogen losses in pigs fed soybean a rapeseed products. Journal of Animal Science, v.76, p.557-568, 1998.

HODGKINSON, S.M.; MOUGHAN, P.L.; REYNOLDS, G.N. et al. Effect of the duration of feeding of a protein - free diet on endogenous ileal nitrogen and amino acid loss in the growing pig. Journal of the Science of Food and Agriculture, v.80, p.1407-1412, 2000.

HODGKINSON, S.M.; SOUFFRANT, W.B.; MOUGHAN, P.J. et al. Comparison of the enzyme-hydrolyzed casein; guanidination and isotope dilution methods for determining ileal endogenous protein flow in the growing rat and pig. Journal of Animal Science, v.81, p.2525-2534, 2003.

HUANG, S.X.; SAUER, W.C.; MARTY, B. et al. Amino acid digestibilities in different samples of wheat shorts for growing pigs. Journal Animal Science, v.77, p.2469-2477, 1999.

JANSMAN, A.J.M.; SMINK, W.; van LEEUWEN, P. et al. Evaluation though literature data of the amount and amino acid composition of basal endogenous crude protein at the terminal ileum of pigs. Animal Feed Science and technology, v.98, p.49-60, 2002.

LAPLACE, J.P. Amino acid availability in pig feeding. In: WORLD CONGRESS OF ANIMAL FEEDING, 4., 1996, Madrid. Anais... Madrid: 1996. v.l, p.109-129.

LENIS, N.P.; BIKKER, P.; MEULEN, J. et al. Effect of dietary neutral detergent fiber on ileal digestibility and portal plux of nitrogen and amino acids and on nitrogen utilization in growing pigs. Journal of Animal Science, v.74, n.11, p.2687-2695, 1996.

LOW, A.G. Digestibility and availability of amino acids from feedstufs for pigs: a review. Livestock Production Science, v.9, n.4, p.511-520, 1982.

MOUGHAN, P.L. Amino acid availability: aspects of chemical analysis and bioassay methodology. Nutriton Research Reviews, v.16, p.127-141, 2003.

MOUGHAN, P.L.; SCHUTTERT, G. Composition of nitrogencontaining fractions in digesta from the distal ileum of pigs fed a protein-free diet. Journal of Nutrition, v.121, p.15701574, 1991.

NYACHOTI, C.M.; LANGE, C.M.; Mc BRIDE, B.W. et al. Significance of endogenous gut nitrogen losses in the nutrition of growing pigs: a review. Canadian Journal of Animal Science, v.77, p.149-163, 1997.

PÖHLAND, U.; SOUFFRANT, W.C.; SAUER, W.C. et al. Effect of feeding different diets on the exocrine pancreatic secretion of nitrogen; amino acids and enzymes in growing pigs. Journal of Science Food Agriculture, v.62, p.229-237, 1993.

POZZA, P.C.; GOMES, P.C.; ROSTAGNO, H.S. et al. Avaliação da perda endógena de aminoácido; em função de diferentes níveis 
de fibra para suíno. Revista Brasileira de Zootecnia, v.32, n.6, p.1354-1361, 2003.

ROSTAGNO, H.S.; ALBINO, L.F.T.; DONZELE, J.L. et al. Tabelas brasileiras para aves e suínos: composição de alimentos e exigências nutricionais. 2.ed. Viçosa: Editora UFV, 2000. 141p.

ROSTAGNO, H.S.; FEATHERSTON, W.R. Estudos de métodos para determinar disponibilidade de aminoácidos em pintos. Revista Brasileira de Zootecnia, v.6, n.1, p.64-76, 1977.
SILVA, D.J. Análise de alimentos: métodos químicos e biológicos. Viçosa, MG: Universidade Federal de Viçosa, 1990. 160p.

STEIN, H.H.; AREF, S.; EASTER, R.A. Comparative protein and amino acid digestibilities in growing pigs and sows. Journal of Animal Science, v.77, p.1169-1179, 1999.

WILIANS, P.E.V. Digestible amino acids for non-ruminant animals: Theory and recent challenges. Animal Feed Science and Technology, v.53, p.173-187, 1995. 